\title{
Desenhos e fotografias: marcas sociais de infâncias
}

\section{Designs and photography: social marks on childhood}

\author{
Marcia Gobbi ${ }^{1}$
}

\begin{abstract}
RESUMO
O presente artigo discute desenhos de crianças pertencentes à primeira infância. Nesta abordagem, desenhos e fotografias são concebidos como formas expressivas e apresentados como fontes documentais importantes para conhecermos diversos aspectos da infância brasileira, bem como suas criações, ao mesmo tempo em que procura suscitar a circulação de ideias sobre criança, infância e suas inventividades, circunscritas a um determinado período de nossa história e cultura.
\end{abstract}

Palavras-chave: infância; desenhos; sociologia da imagem; história.

\begin{abstract}
The present article discusses drawings of children belonging to first infancy. In this approach, drawings and photographs are conceived as expressive forms and presented as important documentary sources for us to know several aspects of Brazilian infancy as well as its creations, at the same time when it looks for exciting the circulation of ideas on child, infancy and its creations, circumscribed to one determined period of our history and culture.
\end{abstract}

Keywords: childhood; drawings; sociology of the image; history.

Neste artigo, os desenhos de meninos e meninas são apresentados como fontes indiciárias a chamar a atenção de adultos e das próprias crianças sobre suas infâncias, vividas há tempos e provocando-nos hoje. Há uma proposição,

${ }^{1}$ Professora do Departamento de Metodologia de Ensino e Educação Comparada da Universidade de São Paulo (USP), Brasil. E-mail: mgobbi@usp.br. 
nesta abordagem, que busca coadunar a perspectiva de compreensão das crianças e suas infâncias à própria história cultural dos desenhos. Não se pretende, com isso, esgotar qualquer discussão sobre essa temática; ao contrário, procura-se estimular o debate sobre esse instigante objeto de estudo, que pode articular-se com diferentes áreas do conhecimento.

Os desenhos das crianças são apresentados nas perspectivas das Ciências Sociais e dos estudos historiográficos. Sabe-se que ambas se constituem como disciplinas distintas que, ao intercambiarem preocupações e procedimentos, oferecem a possibilidade de visões mais ricas e aprofundadas sobre as relações travadas na sociedade e, nessa abordagem especificamente, no que tange aos conhecimentos relativos à primeira infância.

História e Ciências Sociais, embora originalmente não tenham enfocado a infância como um de seus principais objetos de pesquisa, têm em seus campos teóricos importantes referências para se afirmar os desenhos das crianças de todas as faixas etárias como fontes documentais, constituindo-se em documentos históricos.

A prática do desenho, seja em casa ou na escola, e nesta última em todos os níveis de ensino, é considerada uma prática social, portanto, suporte de representações sociais que podemos conhecer. Não são consideradas como retratos da realidade e sim como suas representações, individuais ou coletivas. Inicialmente, aqui os desenhos são concebidos como representações do mundo, ao mesmo tempo em que se constituem como objetos do mundo da representação, revelando-se nas relações com o universo adulto e infantil. Como instrumento, isto lhe permite conhecer melhor aquilo que a criança desenhista é, bem como à própria criança saber mais sobre os outros meninos e meninas que com ela se relacionam, de perto e de longe.

Desavisados, procuramos apaziguar nossos olhares, educados para procurar o que representaria fidedignamente cenas do cotidiano e, com isso, algumas vezes cometemos o equívoco de procurar nessas criações infantis aspectos fiéis à sua realidade. Trata-se apenas do que poderíamos chamar de uma verdade iconográfica, na qual estão presentes a subjetividade do desenhista, a intenção (ou a ausência dela) de rabiscar sem que o rabisco contenha qualquer elemento que o aproxime da realidade. Não é expressão de neutralidade ou mesmo do todo ali representado. É um fragmento que permite, aos olhos sensíveis, refletirem e aprenderem mais sobre os meninos e meninas, ou mesmo sobre seu processo de criação, considerando que são criações e recriações de diferentes realidades. Concebendo a criança como construtora de culturas, seus desenhos podem ser vistos como suportes que revelam aspectos diversos das próprias culturas nas quais está inserida. 
Porém, devo ressaltar aqui que tal consideração refere-se também a uma preocupação com o destino dos desenhos criados pelas crianças desde bem pequenas e como os mesmos eram apreciados pelos adultos que solicitavam às crianças que os criassem, ou mesmo apenas os recebiam como presentes dados nas mais diversas circunstâncias. A pergunta que me faço ao observar desenhos de crianças é: depois de realizado o desenho, das ideias materializadas em traços e rabiscos, em infindáveis formas, tornando-se mais próximas dos outros, quais os caminhos que os desenhos percorrem?

Os diferentes modos como nos relacionamos com estes objetos-desenhos revelam, por sua vez, qual a concepção que se tem daquele que o criou, bem como da própria criação: as crianças em suas diferentes infâncias.

Quando se fala em desenhos infantis como documentos históricos, o propósito é que os mesmos adquiram o peso e a importância de uma fonte documental que traz, entre outros aspectos, a memória da infância e da história do desenho. Além de apresentarem oportunidades para que os adultos e adultas conheçam mais detalhadamente a infância, favorecem a construção de olhares mais detalhados e práticas reflexivas sobre as relações sociais e como as crianças ordenam sua percepção de mundo. É propor uma problematização do mesmo como uma narrativa cultural criada na infância pelas crianças, comportando nisso a imaginação e demais elementos de sua vida. Uma proposta possível de ser implementada é a conjugação entre o desenho e a oralidade que pode revelar, em muitos momentos, como diversos grupos sociais compreendem a si e aos outros. São as culturas infantis que emergem, dando-se a conhecer.

Inspirando-nos em estudos historiográficos e sociológicos para lermos os desenhos das crianças, é interessante que consideremos a comunicação com o grupo social no qual as crianças estão inseridas, considerando que para a criança pequena, sobretudo no ambiente escolar, seus desenhos e diferentes formas expressivas não estão separados do cotidiano destes que são sujeitos históricos. Seus trabalhos resultam de pesquisa pessoal, da interação com outras crianças e com o entorno social e cultural ao qual estão expostas e que ao mesmo tempo constroem. Suas criações são registros, marcas históricas deixadas por elas desde tenra idade.

Mas, o que torna desenhos de meninos e meninas de todas as idades documentos históricos? Como o mesmo pode resistir ao tempo que, em silêncio, pode corroer suas linhas, cores, oxidando não apenas os papéis, como também a memória de tantas infâncias? Qual seu status diante de outras criações infantis? Onde e como os desenhos das crianças podem ser guardados? Devem ser colecionados? Devem ser expostos? E como expô-los?

Os desenhos são criados sobre diferentes suportes de criação (não apenas as folhas com tamanho A4, já quase oficiais e únicas entre as crianças nos es- 
paços escolares), que sustentam e combinam diversas organizações fundindo desejos, imaginação, histórias, formando narrativas numa composição de figuras que podem instigar e exigem olhares também diversos. As culturas vividas e construídas pelos meninos e pelas meninas, no estabelecimento e construção das relações de gênero, emergem documentando uma infância, desde seus traçados concebidos numa primeira olhadela como meros rabiscos sem definição. Registram tempos históricos, marcas históricas de sujeitos de todas as idades, desde que nascem.

Afirmar os desenhos como fontes documentais não significa datá-los simplesmente, trata-se de entendê-los dentro de diferentes contextos de produção, os quais são dinâmicos, curiosos, apresentando contradições. Descortina-se um cenário diante de nós como pistas a serem seguidas. Imagens cujas presenças podem ficar retidas na retina, no corpo, nos diversos espaços frequentados pelos meninos e meninas desenhistas.

Os desenhos, considerados como fontes documentais, são dados, elementos de um tempo, às vezes passado, que permitem conhecer melhor o presente, devendo ser, para tanto, contextualizados. Os desenhos como documentos encontrarão ressonância em abordagens que procuram a ampliação dos objetos de análise sobre as crianças na perspectiva do diálogo com outros campos teóricos, adensando a preocupação sobre as diferentes infâncias construídas socialmente ao apresentar a possibilidade de conhecê-las também por si mesmas em sua pluralidade.

\section{A natureza indiciária nos desenhos criados por meninos e meninas}

Os desenhos possuem um papel cultural, não sendo apenas geradores de encantamento nos adultos. Todos os desenhos são frutos de um processo de criação que se articula com outras formas expressivas dos seres humanos.

A dinâmica entre os tempos históricos, também percebida através dos desenhos e com os desenhos e seus desenhistas, pode provocar a percepção de uma "circularidade cultural", nos moldes preconizados por Carlo Ginzburg, inspirado em Bakthin, entre os diferentes níveis de cultura, de faixas etárias, gênero e classes sociais. Cabe nos investirmos de uma curiosidade investigativa destes tantos traços que desenham e redesenham infâncias e mundos. $\mathrm{O}$ conceito de "circularidade" de Bakhtin, utilizado por Ginzburg, em seu O queijo e os vermes, se coaduna com esta ideia, já que propõe uma "circulação" entre a cultura das classes dominantes e dominadas, entre as diferentes construções sociais dos 
seres humanos. Desta forma, então, a cultura se apresenta de forma dinâmica. Significa dizer que não existe um modelo fechado, uma via de mão única para o estudo das culturas infantis, mas não só, já que experiência advinda dessa troca torna-se plena de possibilidades, constituindo seus desenhos elementos que devem ser considerados importantes na trama social.

Essa observação revela a infância ao garantir sua fala, dando espaço para a mesma a partir das construções das crianças, de suas brincadeiras, seus jogos, seus processos de elaboração de conhecimentos, em que o desenho é uma das linguagens apresentadas, assim como esculturas, engenhocas, enfim, suas criações. É um registro para além dos registros fechados e empoeirados que pulsa e faz pulsar, aos quais podemos associar a coleta de desenhos ou tantos outros documentos, tais como a fotografia, de maneira a compreender melhor os indícios revelados por eles.

Ao nos voltarmos para a prática de coleta de desenhos, a perspectiva de que essa forma expressiva de meninos e meninas pode ser tratada como fonte documental nos remete a observá-los de modo ainda mais denso, trata-se de perscrutar seus traços e cores, investigá-los como algo estranho aos nossos olhares, trazendo um universo que revela o visível e o invisível de suas tantas relações. São mensagens simples e até óbvias ou complexas, pouco claras, e que não contêm a verdade incontestável. Trata-se de um patrimônio da produção dos pequenos e pequenas, sua construção pessoal e coletiva expressão das culturas da infância. Arquivar, guardar, desprende-se do ranço preconceituoso para aqueles que acreditam que nisto resida uma associação ao que está "morto" ou deva ser desprezado. Ao contrário, guardar e expor tais desenhos significa a preservação da memória de nossa infância e dos registros de sua passagem pela história.

No que se refere à criação de desenhos, quando nossas preocupações se voltam para uma perspectiva social, algumas perguntas podem ser feitas: de maneira geral, há diferença na escolha dos temas pelos meninos e pelas meninas? Há motivos artísticos mais predominantemente encontrados nos desenhos de um ou de outro? Há elementos que evidenciam cenas de um cotidiano vivido pelos meninos ou pelas meninas? Os riscos modificam-se ao longo do tempo? Ao serem conjugados à fala das crianças desenhistas, outros desenhos ou outras formas de compreendê-los são revelados? Como os mesmos podem se oferecer de modo a percebermos narrativas do cotidiano e da imaginação próprias dessas crianças? Há diferenças étnicas perceptíveis? Formas de ocupação do espaço do suporte oferecido para desenhar? Quais as cores mais frequentemente utilizadas para expressar pessoas brancas ou negras? Há o já famoso pedido do "lápis cor de pele" para pintar pessoas, indiferentemente, como se todos nós tivéssemos a mesma cor de pele, denunciando um padrão de beleza a ser seguido? 
Enfim, são muitas as questões que poderíamos levantar. Porém, deve-se salientar que são fundamentais para pensarmos a criação de desenhos a partir de olhares que os investiguem, considerando as relações sociais estabelecidas pelos meninos e meninas em suas brincadeiras, na convivência com os adultos, nos espaços escolares ou fora deles, construindo suas culturas, expressando aspectos do multiculturalismo que podem ser considerados. Revelam visões mais ricas e aprofundadas das relações estabelecidas em sociedade e mesmo expressões da imaginação infantil que, tantas vezes, passam ao largo do pensamento e da compreensão dos adultos.

Certamente o desenho e seus índices são pistas que não podem ser tomadas como verdades históricas, o que, aliás, acontece também com a fotografia ou tantos documentos, quando nos referimos à história demográfica, estando sujeitos a diferentes interpretações. Trata-se de uma verdade iconográfica apenas, rica por excelência, mas que não é copia fidedigna da realidade, mesmo porque estou chamando a atenção para os desenhos considerados rabiscados, criados pelas crianças bastante pequenas, o que serve como marca de sua presença em determinado período da história, porém, não como retrato da mesma.

No Brasil, na procura por observar a criação de desenhos de meninas e meninos em sua primeira experiência discente em uma escola municipal de São Paulo, pesquisei minuciosamente os elementos encontrados em seus desenhos e, conjugando-os à oralidade e a entrevistas com os pais das crianças desenhistas, outro cenário se abre: algumas mudanças, as quais chamei de transição, nas relações mantidas entre homens e mulheres, na concepção que têm das mesmas e na própria construção das relações de gênero. Apontava à época para um período no qual se anunciavam alterações quanto ao relacionamento familiar e ao mantido pelos pais e mães, entre estes e seus filhos, que acenam também para novas formas de criação de filhos e filhas. Nos desenhos, viam-se mulheres ao redor de pias, de fogões, apetrechos utilizados pelos pais no trabalho, tais como a maleta, que aparecia em vários dos desenhos, panelas e utensílios domésticos ao lado das mulheres. Mas, será que o espaço doméstico ainda é de uso exclusivo das mulheres? Os homens estão sempre dentro dos carros? O que leva meninos e meninas perceberem homens e mulheres ocupando seus espaços da maneira como demonstravam nos desenhos e nas falas? Qual o contexto social que está exposto?

$\mathrm{O}$ estudo minucioso dos desenhos permite-nos investigar como tais relações sociais estão sendo construídas. A partir destas expressões, é possível procurar conversar com as crianças desenhistas e com isso conjugar seus desenhos a outra linguagem, compondo narrativas de uma infância que não está em estado de espera daquilo que virá posteriormente, numa perspectiva de 
encontrar homens e mulheres prontos, modelos a serem seguidos. Ao contrário, os percebem, representam e constroem no tempo vivido de modo concomitante.

Num breve exercício de olharmos ao redor, nos muros e paredes escolares, bem como em pastas silenciadas onde tantas vezes encontram-se os desenhos das crianças, é possível perceber a escrita da professora indicando, ao lado do desenho, aquilo que foi dito enquanto desenhava. Não é raro, portanto, encontrarmos as palavras sol, flor, menina, mãe, casa denominando os traços, sobretudo das crianças bem pequenas, cujas composições parecem indecifráveis aos adultos. Desta forma, ao escrever, a professora apazigua seu próprio desejo de compreender o que fora criado pela criança, bem como o torna mais compreensível aos olhos dos outros que compartilham com ela o espaço de trabalho, ou, ainda, aos familiares das crianças que porventura entrem em contato com o que fora realizado.

O que está em pauta aqui são as relações socioculturais que se descortinam e proporcionam de modo concomitante que formulemos ideias sobre a criança desenhista ao conhecermos seus desenhos. Tais criações seriam instrumentos nas mãos de profissionais da educação. Documentam a realidade vivida não com a pretensão de serem cópias do real e podem servir como fontes para reflexão e até mesmo transformação do contexto social, histórico e cultural vivido.

Embora atemporal, a imagem-desenho de meninos e meninas, finita e infinita em possibilidades diante de nossos olhos, numa primeira olhadela sobre o resultado da composição em folhas de papel, areia, terra, provoca-nos, ao sugerir ser fonte informante, que rabisca e traça e que apresenta marcas de crianças plenas em suas complexidades, imagens criadas, alimentadas em maior ou menor escala, apresentando também seus pontos de vista. Se as imagens, por sua vez, buscam palavras, inquietos que somos tantas vezes, querendo expor os sentimentos, elaborar ideias sobre o que vemos, põem diante de nossos olhos vestígios, registros rabiscados ou figurados de maneira mais compreensível ao universo adulto, dizem de infâncias. Basta ouvi-las e lê-las.

\section{Desenhos como pistas em diálogo com as fotografias}

Historicamente, a compreensão que se tem sobre os desenhos das crianças vem passando por um processo de transformações. Nessa dinâmica, atribuo às próprias crianças uma grande contribuição relativa à construção de olhares para as criações infantis. Isso se dá na medida em que as mesmas, ao dialogarem mais com os adultos e adultas ao mesmo tempo em que criam, colaboram para 
o entendimento dessas produções, alertando aos atentos por conhecer as crianças e suas criações. Contudo, a perspectiva de um tratamento voltado para uma criança cujos desenhos são inferiores aos do adulto, bem como sendo os mesmos percebidos apenas como processo de desenvolvimento psíquico infantil, ainda convive com demais concepções. Tais convicções reduzem a criação infantil a um patamar apenas instrumental: para que os(as) professores(as) avaliem.

Os desenhos são imagens que possuem uma natureza indiciária, como já afirmado aqui, na medida em que permitem a descoberta de pistas vistas ou não, experimentadas ou não por nós. Devem ser acrescidos de informações de outras ordens ou áreas de conhecimento e desta maneira privilegiando ampliar o leque de indícios ou mesmo de fontes a responder sobre uma temática, neste caso em especial, a infância. Desta forma, agrego aos desenhos as fotografias do período em que os meninos e meninas referidos os realizaram, concentrando-me nos anos entre 1935 e 1938 na cidade de São Paulo, em seus parques infantis. É ir além dos desenhos e voltar a eles, implicando a busca por percebermos as teias que o enlaçam ao contexto histórico de sua produção. Aquilo que aparentemente está oculto encontra-se com o explícito como respostas ao desenho, ao contexto, à infância dos desenhistas e à nossa própria infância atual. $\mathrm{O}$ desenho nos mostra algo sobre si próprio e sobre os desenhistas que os compuseram, porém, há elementos circunscritos, no espaço e no tempo, há significados que o ultrapassam. São fatos que somados revelam sua história, sua criação, revelam e despistam aquele que os olham. São fragmentos que se dão a conhecer e que se escondem. São desenhistas pequenos e anônimos que surgem. Seguir procurando conhecê-los é algo fundamental para a história, para os campos teóricos da educação e, sobretudo, para a própria infância.

Nas fotografias do acervo fotográfico Benedito Duarte, é possível percebermos tanto os contextos de produção das crianças como o interesse pelo que estavam fazendo, pela observação de seus corpos, que se debruçam sobre os papéis e diferentes materiais. Contudo, ao observar melhor, percebe-se que, nas fotografias tiradas no mesmo local, em 1937, no Parque Infantil do Ipiranga, há instrumentos que poderiam orientar a criação dos desenhos, tais como réguas e quadros de imagens para desenhos de observação, o que teria originado a distinção entre desenhos de imaginação ou não (escritos nas produções das crianças maiores de seis anos). Barbosa (2001) afirmará que, nos anos de 1930, os pedagogos defendiam o desenho pedagógico, cuja base era a cópia de formas simplificadas de objetos desenhados pelo professor. Na afirmação a seguir, sobre um conjunto de desenhos que estudava, Mário de Andrade manifesta sua discordância a respeito: 
Infelizmente a professora pelo menos às vezes apresentava gravuras incitando as crianças à reprodução. Daí certas coincidências e certas sabedorias inúteis em alguns dos desenhos. (Documento do acervo MADI 1025).

Novamente, o que vemos é a não orientação sendo privilegiada por Mário de Andrade. $\mathrm{O}$ que deve ser destacado é que as orientações de Mário deveriam se chocar com os ensinamentos da época. A formação recebida pelas professoras no Curso Normal, condição exigida para atuar nos Parques Infantis, compunha-se de disciplinas curriculares e estágios obrigatórios, leituras de livros e revistas especializados, cujos ensinamentos eram cultivados entre as alunas que os reproduzirão junto às crianças tantas vezes na forma de busca por uma reprodução fotográfica do desenho.

$\mathrm{Na}$ Escola Caetano de Campos, ao lado dos laboratórios de física, química e biologia, foi criado o laboratório de psicologia experimental com o objetivo de montar um gabinete psicotécnico com aparelhos para experiências no campo de medidas de inteligência, avaliação de aptidões e testes profissionais. Sabe-se que a psicologia entra na Escola Normal de São Paulo pelas mãos de discursos e equipamentos que potencializaram a autoridade dos campos educativos, bem como, dos especialistas em educação, modificando assim, o caráter e a prática educativa.

Conforme a política educacional instituída no decreto assinado em 21 de abril de 1933, cujo conteúdo será publicado na Revista de Educação n. ${ }^{\circ} 2$ do mesmo ano como Código de Educação, seu interesse volta-se às normatizações estabelecidas, que vão desde questões funcionais dos profissionais da educação até a formação e os componentes curriculares, metodologias que diziam respeito estritamente à organização pedagógica. Com isso, a professora era chamada a rever suas práticas consideradas rotineiras, repetitivas e antiquadas. Ao mesmo tempo em que esses aspectos eram avaliados, fundamentando-se em novas teorias pedagógicas inspiradas em pesquisas recentes, o Código de Educação, por meio de seus dispositivos, delimitava o espaço de atuação criativa e espontânea do fazer educacional de professores e alunos. O imprevisível não estava contemplado e deveria ser encaixado em formas de regulação social (MATE, 2002).

Tínhamos a sobrevivência de princípios de caráter funcionalista, no qual a escola detinha o papel de conformação dos alunos à sociedade, tendo no professor a voz responsável pela propagação e perpetuação das normas, com novas técnicas pedagógicas e formas de pensamentos avançados para a época, contemplando um caráter reformista, percebido, sobretudo, nas revistas publicadas, tais como Escola Nova, de 1930, que, posteriormente, passa a ser chamada de Revista de 
Educação. Esta se notabiliza por seu primeiro número, no qual divulga o Manifesto dos Pioneiros em Educação com o título "A Reconstrução Educacional do Brasil: ao povo e ao governo", redigido por Fernando de Azevedo. Seu objetivo é veicular grande parte das ideias presentes no pensamento pedagógico da época, constituindo-se, portanto, como matrizes teóricas desse pensamento ${ }^{2}$.

Propunha-se, assim, a redução dos corpos das crianças a algo que devia ser mensurado por técnicas, repartindo-os: mãos que desenham separam-se dos olhos, do pensamento, do ritmo, da dança, da brincadeira. Ao mesmo tempo, Mário de Andrade solicitava às instrutoras que não interferissem nas criações de desenhos, propondo que os trabalhos manuais, a dança, a escultura, o folclore, a marcenaria se diluíssem no cotidiano dos Parques Infantis. Tratava-se de uma orientação coerente com a pedagogia ${ }^{3}$ de Mário de Andrade, que, talvez, de tão avançada para a época, ficasse retraída entre as práticas mais conservadoras, convivendo com elas, encontrando ressonância e discordância simultâneas, num processo de criatividade intelectual com características transformadoras e dinâmicas, mas também reprodutoras, fato sempre presente nas instituições educacionais ${ }^{4}$.

Compondo o exercício de olhar sobre os desenhos, nas fotografias o que pode ser visto são quadros de figuras com imagens de paisagens copiadas pelas crianças ou que, pelo menos, parecem induzir à cópia. Alguns materiais, dentre eles as réguas, são marcantes na mesa, entre os papéis e os lápis, o que, sem dúvida, ajudaria na composição das molduras, tão presentes na maioria dos desenhos do acervo, nas produções das crianças de todas as idades, construindo uma cultura do desenho que, ao mesmo tempo em que procura valorizar-se, desconsidera seus múltiplos aspectos, enquadra-o e é enquadrada por ele, por determinações de uma época que trará alguns estereótipos significativos de tais criações. A utilização da régua como instrumento que auxiliará na construção de desenhos encontra-se não apenas nas molduras, como também nos desenhos contidos no interior das margens.

${ }^{2}$ Vale ressaltar que desde 1901 tínhamos, entre os livros adotados pelos professores da Escola Normal, aqueles que continham as edições do professor com as respostas. Quanto à introdução de métodos de ensino, um dos primeiros a difundi-los foi o livro Primeiras lições de coisas, que objetivava inserir o método intuitivo entre as normalistas, adaptado do original inglês, publicado desde 1861.

${ }^{3}$ Vale ressaltar que Mário de Andrade em suas reflexões não se afirmava como pedagogo, o que não era.

${ }^{4}$ E não só. Como afirma Santiago (1989), a tradição está presente na modernidade e no modernismo, demonstrando os seus resquícios do discurso da tradição ao lado da estética nitidamente futurista. Santiago apresenta como exemplo a viagem realizada por Mário de Andrade e Tarsila do Amaral, em 1927, a Minas Gerais, visitando e se encantando com a cidade de Ouro Preto. 
A maior parte das crianças desenhistas fotografadas é composta de meninos e meninas com mais de seis anos, mas as idades se misturam, o que serve como pista para pensarmos sobre propostas educacionais segundo as quais as crianças não precisam permanecer em tarefas segundo divisão de sexos.

É possível observar pelas fotografias que há meninas e meninos sem camisa que, junto daqueles com camisetas, provocam nossos olhares diante dos corpos das crianças que se expõem e documentam uma época, permitindo escrever parte da história da educação pública paulistana e infantil. Essa convivência entre crianças de diferentes idades, sob a sombra das árvores, sem camisa, desenhando ao ar livre, compunha o dia a dia. Em algumas mesinhas, observa-se a postura das crianças, voltadas para a professora ${ }^{5}$ ou para o menino que, em pé, entrega o lápis, talvez numa espera ansiosa pelas folhas onde desenhar, que ainda se encontravam nas mãos da professora. Alguns gestos das crianças, por exemplo, o pescoço virado para trás, procurando olhar os outros para comunicar-se com eles, e a menina em pé, denotam a convivência com um mobiliário de características mais escolares presentes no espaço de fora. Evoca-nos a pergunta: uma sala de aula a céu aberto? As mesas, as cadeiras, as crianças sentadas assemelham-se à constituição espacial escolar; contudo, a mistura de diferentes idades - embora predominem as crianças maiores -, a própria área livre, as mesas ocupadas por várias crianças de modo diferente do mais tradicional (enfileiradas umas atrás das outras) denunciam a convivência com a diversidade, o desejo e a sugestão de utilização de espaços diferenciados pelas crianças, e nisso diferem bastante dos padrões escolares, que, insistentes, mantêm as crianças fechadas em salas de aulas, a ver apenas nucas ou cabeças dos companheiros que ficam à sua frente. Trata-se de um formato escolar que convivia com a proposta transgressora do Parque Infantil.

Ao analisarmos fotografias, é importante não as considerarmos apenas como prova incontestável, definitiva de um dado da realidade. Sua importância encontra-se no cruzamento entre diferentes elementos quando podemos, como nos ensina Kossoy (2000), encontrar as realidades exterior e interior existentes na imagem fotográfica e que dão margem à criação de diferentes realidades.

Ao observarmos as fotografias, os corpos das crianças também chamam a atenção como territórios que conduzem nossos olhares e que portam em si o peso e a leveza da infância. Elas por si contribuem para a construção da "história dos corpos das crianças". Esses "corpos-territórios" (VIGARELLO, 2003) nos permitem aprender também com eles, conhecendo-os, ainda que por fotos, às vezes, já desgastadas pelo tempo.

${ }^{5}$ A postura do corpo da professora remete à afirmação de Leite (1993) de que as mulheres fotografadas entre os séculos XIX e XX mantinham, em sua maioria, certa sisudez. 
A partir dos olhos do fotógrafo Benedito Duarte, que fotografou em profusão as crianças frequentadoras dos parques infantis da cidade de São Paulo nas primeiras décadas do século XX, o que pode ser também conhecido é uma postura diferente daquela presente nas primeiras décadas do século $\mathrm{XX}$, segundo a qual o objeto da fotografia deveria ser o espaço físico construído - uma característica marcante nas primeiras décadas da República-, que deveria deixar suas marcas demonstrando o progresso que se instaurava, com sua exuberância e ecletismo arquitetônicos. Com Benedito Duarte, o espaço arquitetônico perdia seu lugar em relação às crianças, que se tornavam protagonistas das cenas, estas, sim, o alvo de sua objetiva. Duarte se contrapunha a um padrão presente nas revistas produzidas para os leitores ricos, nas quais os corpos das crianças eram revelados com trajes semelhantes àqueles usados por adultos, em lugares onde a pobreza não aparecia (BRITES 2000). Procurava-se esconder ou transformar a miséria e a sua estética, revelando uma imagem idealizada de infância. Duarte inaugura um olhar fotográfico que, ao colocar a criança em foco, permite àquele que olha reconhecê-la também em suas singularidades.

Essa informação é importante, pois o fotógrafo, ou melhor, o que o mesmo propõe é fundamental para compreendermos a própria imagem, bem como seus receptores. Ambos criam realidades a partir de seus objetivos e de suas experiências culturais, com o material fotográfico, com o objeto a ser fotografado. Trata-se de considerar não apenas a fotografia, mas tudo o que está em seu entorno.

\section{REFERÊNCIAS}

ANDRADE, Mário de. Primeiro de Maio. In: Contos novos. São Paulo: Itatiaia, 1939. . O pai do gênio. In: ANCONA LOPEZ, Telê (Org.). Táxi e crônicas no Diário Nacional. São Paulo: Duas Cidades, 1976. p. 276-279.

. Da criança prodígio I e II. In. ANCONA LOPEZ Telê (Org.). Táxi e crônicas no Diário Nacional. São Paulo: Duas Cidades, 1976. p. 129-134.

. Da criança prodígio III. In: ANCONA LOPEZ TELÊ (Org.). Táxi e crônicas no Diário Nacional. São Paulo: Duas Cidades, 1976. p. 137-138.

BARBOSA, Ana Mae (Org.). Arte-educação: leitura no subsolo. São Paulo: Cortez, 1997. . A arte-educação no Brasil. São Paulo: Perspectiva, 1995. . John Dewey e o ensino da arte no Brasil. São Paulo: Cortez, 2001. 
BRITES, Olga. Crianças de revistas. Educação e Pesquisa. Revista da Faculdade de Educação da USP, n. 25, p.161-178, jan./jun. 2000.

. Pintura infantil. In: ANCONA LOPEZ TELE (Org.). Táxi e crônicas no Diário Nacional. São Paulo: Duas Cidades, 1976. p. 277-279.

. Do desenho. In: Aspectos das artes plásticas no Brasil. São Paulo: Itatiaia, 1975. p. 71-77.

CEPPI, Giulio; ZINI, Michele. Bambini, spazi, relazioni: metaprojeto di ambiente perl'infanzia. Reggio Emilia: Reggio Childreen, 1998.

50 ANOS DE PRÉ-ESCOLA MUNICIPAL. Revista Escola Municipal, São Paulo: Secretaria Municipal da Educação, v. 18, n. 13, 1985.

DEMARTINI, Zeila B. F. Infância, pesquisas e relatos orais. In: FARIA, A. L.; DEMARTINI, Z.; PRADO, P. D. (Orgs.). Por uma cultura da infância: por uma metodologia de pesquisa com crianças. Campinas: Autores Associados, 2002.

FARIA, Ana Lúcia Goulart de. Direito à infância: Mário de Andrade e os Parques Infantis para as crianças de família operária na cidade de São Paulo (1935-1938). Tese (Doutorado) - Faculdade de Educação, Universidade de São Paulo, 1993.

FERRARA, Lucrécia D'A.; VERNASCHI, Elvira (Orgs.). O ensino das artes nas universidades. São Paulo: Edusp/CNPq, 1993, p. 59-70.

KOSSOY, Boris. Realidades e ficções na trama fotográfica. Cotia: Ateliê, 2000.

LEITE, Maria Isabel (Org.). Ata e desata: partilhando uma experiência de formação continuada. Rio de Janeiro: Ravil, 2002.

LEITE, Miriam M. Retratos de família. São Paulo: Edusp, 1993.

MATE, C. H. Tempos modernos na escola: os anos 30 e a racionalização da educação brasileira. 1. ed. v. 1. Bauru: EDUSC, 2002. 180 p.

STACCIOLI, Gianfranco. Disegnare per crescere. Bambini, Bergamo: Edizione Junior, anno XII, n. 0, nov. 1996.

. Immagine fatte ad arte: idée ed esperienze per educare alla comunicazione visiva. Roma: Carocci, 2002.

VIGARELLO, Goerges. A história e os modelos do corpo. Revista Pro-posições, v. 14, n. 2(41), p. 21-31, 2003.

Texto recebido em 11 de agosto de 2009.

Texto aprovado em 02 de novembro de 2009. 